\title{
"Para el bien de la Nación”. Gestión militar de empresas estatales, prácticas de integración y represión de la fuerza de trabajo desde la perspectiva de caso. El Astillero Río Santiago 1973-1976
}

\author{
Ivonne Barragán \\ Universidad de Buenos Aires - \\ Facultad Latinoamericana de Ciencias Sociales \\ ivobarragan@yahoo.com.ar
}

\begin{abstract}
Resumen
El rol de las fuerzas armadas como actores centrales de la escena política en Argentina ha sido abordado desde múltiples perspectivas por la historiografía y las ciencias sociales en general. Sin embargo, su accionar en la gestión de empresas estatales y la constitución de un tipo de relaciones laborales muestran escasos aportes. Este trabajo propone una mirada sobre las interrelaciones existentes entre las prácticas empresariales y las formas de organización y lucha obrera durante el período de intensificación del conflicto social y tercer gobierno peronista comprendido entre los años 1973-1976 a partir de la perspectiva de caso. Trabajaremos en profundidad el Astillero Río Santiago (ARS) de Ensenada que era una empresa de capitales públicos, cuya dirección correspondió a la Marina de Guerra, y ostentó un alto grado de diversificación productiva. Abordaremos el desarrollo de aquellos planteos empresariales que -en el marco de una ideología de desarrollo industrial para el crecimiento de la nación-promovieron una relación contractual de "privilegio y beneficio relativo" y, análogamente, desplegaron crecientes acciones de violencia, coerción y represión sobre la fuerza de trabajo ante el desarrollo de la conflictividad obrera.
\end{abstract}

Palabras Clave: Militares - Gestión - Organización del trabajo - Paternalismo autoritario - Nación - Violencia

\begin{abstract}
Historiography and social science in general have analyzed the role of the military forces as key central actors in the Argentine political scene. However, its specific actions within state and military managment companies and the concurrent development of labor relations have had little attention. This paper poses an aproach to this issue by addressing the relationships between managment and labor organization and struggle in the case study of Astilleros Rio Santiago during the last phase of Import Substitution Industrialization.

This brief paper aims to analyze the complex relationship between two social processes in 1974-1976.
\end{abstract}

BARRAGÁN, Ivonne, “'Para el bien de la Nacion’. Gestión militar de empresas estatales, prácticas de integración y represión de la fuerza de trabajo desde la perspectiva de caso. El Astillero Río Santiago 1973-1976", en Avances del Cesor, Año X, N $N^{\circ} 10,2013$, pp. 53-72. 
We address the process of grassroots organization and mobilization at the Rio Santiago Shipyard (Astillero Rio Santiago) in dialogue with those management actions and practices that can be defined as a sort of authoritarian paternalism. It is our hypothesis that the display of disciplinary, coactive and repressive measures over the workforce pursued the hegemonic recomposition of the military order in the factory prior to the 1976 Coup d'Etat.

Key Words: Military - Managment - Labor organization - Authoritarian paternalism - Nation - Violence

\section{Introducción}

El rol de las Fuerzas Armadas como actores centrales de la escena política en Argentina ha sido abordado desde múltiples perspectivas por la historiografía y por las ciencias sociales en general. Sin embargo, su accionar en la gestión de empresas estatales y la constitución de un tipo de relaciones laborales muestran escasos aportes. En este trabajo proponemos una mirada sobre las interrelaciones existentes entre las prácticas empresariales y las formas de organización y lucha obrera durante el período de intensificación del conflicto social y tercer gobierno peronista comprendido entre los años 1973-1976 a partir de la perspectiva de caso, el Astillero Río Santiago ${ }^{1}$ de Ensenada. El ARS ${ }^{2}$ era una empresa estratégica, de capitales públicos, cuya dirección correspondió a la Marina de Guerra, y ostentó en este período un alto grado de diversificación productiva (producía y reparaba unidades navales civiles y militares y bienes de capital para la industria metal-mecánica).

Nos preguntaremos, en esta primera aproximación sobre la reposición de las Fuerzas Armadas y la Marina específicamente como sujeto empleador, si la apelación sostenida por la dirección del astillero al "bien de la nación” constituyó un insumo de legitimación de la gestión empresarial de la fuerza de trabajo de manera de lograr hegemonía en la fábrica. A partir de este interrogante, indagaremos sobre las relaciones entre aquellos planteos empresariales que -en el marco de una ideología de desarrollo industrial para el crecimiento nacionalpromovieron una relación contractual de "privilegio y beneficio relativo" y, análogamente, desplegaron crecientes acciones de violencia, coerción y represión sobre la fuerza de trabajo, específicamente, ante el desarrollo de un ciclo ampliado de conflicto protagonizado por sus trabajadores en el período 1973-1976.

1 En adelante ARS.

2 El ARS fue creado mediante el Decreto del Poder Ejecutivo Nacional (PEN) No 10.627 del 15 de junio de 1953 y con la Fábrica Naval de Explosivos de AZUL (FANAZUL) conformaron la empresa estatal Astilleros y Fábricas Navales del Estado (AFNE). 


\section{El Astillero: "voluntad nacional construyendo para el mar"3}

El conjunto de las Fuerzas Armadas, ya a partir de las primeras décadas del siglo XX, expresaron en su seno la conformación de distintas facciones que pugnaban por un nuevo rol del Estado como interventor en el desarrollo nacional y, puntualmente, por el desarrollo industrial como forma de asegurar la autonomía estratégica con respecto a los países de la región y al contexto internacional de la primera posguerra. El punto de convergencia industrial-militar se consolidó en la década del ' 40 en base a dos necesidades: industrializar al país para proveer a la defensa y prevenir el conflicto social. ${ }^{4}$

Dicha convergencia volcada al desarrollo industrial reservó para las fuerzas armadas lugares de privilegio en la estructura de gestión del Estado y en la construcción de un complejo industrial militar complejo y diversificado. La construcción de un conjunto de fábricas estratégicas gestionadas por las tres fuerzas funcionó en esta etapa, en la práctica, como compartimentos estancos, es decir, cada fábrica abasteció las necesidades de la fuerza a la que pertenecía. ${ }^{5}$

Gustavo Pontoriero propone discutir la tradicional tesis que identifica las ideas industria-

3 Eslogan publicitario de la empresa hasta los años ochenta.

4 Nuestra aproximación a este desarrollo histórico será sólo de forma referencial de manera de dar un marco al caso propuesto. Ver, para una perspectiva general, TORCUATO DI TELLA, "Industria, Fuerzas Armadas y peronismo" en MORENO, Oscar (coordinador) La construcción de la Nación Argentina. El rol de las Fuerzas Armadas, Ministerio de Defensa, Buenos Aires, 2010. Para una aproximación especializada que despliega las contradicciones entre las distintas facciones al interior de las FFAA una vez consumado el último golpe de Estado, ver CANELO, Paula, El proceso en su laberinto. La interna militar de Videla a Bignone, Prometeo, Buenos Aires, 2008.

5 Beyreuther sostiene que, en términos generales, la administración de las empresas se ordenó de la siguiente manera: el mayor número de empresas, enmarcadas en lo que fue la Dirección General de Fabricaciones Militares (DGFM), correspondió al Ejército; la Fábrica Militar de Aviones de Córdoba, a partir de 1945, pasó a depender de la Secretaría de Aeronáutica, y a la Marina le correspondió la gestión de AFNE, que comprendía el ARS y distintos talleres navales y tuvo intervención en la industria petrolera. A fin de explicitar la relevancia del caso propuesto tomaremos la caracterización de la autora. Beyreuther define a las industrias estratégicas como "aquellas que, por sus características (efectos de aprovisionamiento y propulsión) conforman polos de desarrollo multiplicadores, siendo fundamentales para el desarrollo económico, tecnológico e industrial de un país. En ese sentido, responden a esta concepción: la industria energética (petróleo y gas), industria siderometalúrgica, industria nuclear, industria química (química pesada y petroquímica) e industrias para la defensa (Industria naval, industria de armamentos, industria aeronáutica e industria espacial), y por supuesto, las vinculadas a las TICs." Ver BEYREUTHER, Irene, "Desarrollo científico tecnológico e Industrias para la Defensa" ponencia presentada en las IX Jornadas de Sociología. Capitalismo del Siglo XXI, crisis y reconfiguraciones, Universidad Nacional de Buenos Aires, Agosto de 2011. 
listas con el Ejército en contraposición a una Armada anglófila de posiciones más liberales. ${ }^{6}$ En el interior de esta fuerza existieron fuertes facciones que sostenían el necesario impulso a la intervención estatal en la explotación de recursos estratégicos para la defensa en un posible escenario de guerra. La preocupación por lograr el autoabastecimiento de buques e insumos para la Marina de Guerra promovió, a partir de las escuelas navales, la consolidación de una elite técnica, el impulso a la exploración, la investigación y el desarrollo científico, y la gestión de empresas de enorme relevancia e impronta en el desarrollo de las regiones en que se encontraban enclavadas.

El ARS perteneció al segmento más dinámico de la economía del modelo de Industrialización por Sustitución de Importaciones (ISI), su directorio se conformó por militares pertenecientes a la Fuerza Naval. En 1969 se constituyó como Sociedad Anónima del Estado con mayoría accionaria en poder del Ministerio de Defensa y en 1976 el Comando en Jefe de la Armada tomó el control de la empresa accediendo al paquete accionario mayoritario.

El Estado cumplió un rol protagónico en la conformación y sostenimiento de la demanda. El ARS producía y reparaba unidades navales militares. Si bien en la industria naval llamada "pesada", cada empresa puede ser identificada por la producción especializada en algunos de los segmentos de la rama -transporte de carga, transporte de pasajeros y pesquera- el ARS superó su especificidad a partir de la construcción de buques tanque, graneleros, cargueros, pesqueros, frigoríficos, buques de pasajeros, de recreación y deporte, embarcaciones auxiliares y artefactos navales. ${ }^{7}$ Paralelamente, diversificó su producción hacia la fabricación de bienes de capital durables e insumos industriales dirigidos hacia el mercado interno - grandes motores eléctricos, tanques de envase; elementos y maquinarias para la actividad ferroviaria; compuertas para diques; equipos de bombeo para la industria petrolera; fundición de aceros, hierros y metales; maquinaria para las industria del azúcar y del papel y la construcción de turbinas hidráulicas para centrales hidroeléctricas- ${ }^{8}$ En la década del ' 70 , el ARS también fabricaba motores para buques con licencia de Sulzer y Fiat, motores que salían con la marca ARS SULZER y ARS FIAT9.

6 PONTORIERO, Gustavo, "Fuerzas Armadas y desarrollo energético en la Argentina: el papel de la Marina de Guerra en la primera mitad del siglo XX", en Revista H-industri@ Revista de historia de la industria, los servicios y las empresas en América Latina, Buenos Aires, primer semestre de 2012, año 6, $\mathrm{N}^{\circ} 10$.

7 Síntesis de la Economía Real № 51, Centro de Estudios para la Producción, SEPYME, Ministerio de Economía, Marzo 2006, p. 13.

8 CAFFASO, María Elena, Astillero Río Santiago, AFNE, Buenos Aires, 2004. 


\section{La gestión de la fuerza de trabajo}

Nuestro abordaje de las relaciones laborales y el conflicto obrero en el caso del ARS parte de considerar la singularidad del caso - una empresa de capitales públicos ${ }^{9}$, de producción estratégica, administrada por una fuerza militar- y toma como insumo los estudios que sostienen que todo ordenamiento productivo requiere de un grado constitutivo de violencia en simultaneidad a la construcción de cooperación. ${ }^{10}$

En el ARS el sistema de cooperación y dominio simultáneo sostenido sobre la fuerza de trabajo tuvo diferentes expresiones. ${ }^{11}$ La dirección de la fábrica configuró una relación laboral que propiciaba la incorporación de los trabajadores a los intereses de la empresa a partir de una idea de relación laboral beneficiosa para ambos términos con fuerte anclaje en valores nacionalistas. De manera análoga, sostuvo una serie de prácticas fundamentadas en la disciplina como mecanismo de poder y de habituación a un orden productivo de fuerte carácter militarizado que implicaron instrumentaciones diferenciales de violencia material y simbólica. ${ }^{12}$ A partir de los elementos indicados, proponemos un diálogo con aquellos

9 Carmen Alveal Contreras señala el carácter dual de las empresas estatales. Las mismas contienen las necesidades propias a cualquier emprendimiento capitalista -lucro/defensa socios- en relación con los intereses políticos-nacionales, estratégicos, etc. ALVEAL CONTRERA, Edelmira del Carmen, Os desbravadores: a Petrobras e a construção do Brasil industrial, ANPOCS, Rio de Janeiro, Relume-Dumará, 1994, Citado en ALEX de SOUZA, Ivo, "Em nome da nação... e dos trabalhadores: a construção da identidade sindical dos petroleiros (Bahia, 1959-1985)", ponencia presentada en las VI Jornadas de Historia del Trabajo y II Seminario Internacional Mundos del Trabajo del GT Mundos del Trabajo de la ANPUH Río de Janeiro, noviembre de 2012, p. 2.

10 Algunas referencias del campo principal de aportes teóricos que nutren nuestra perspectiva: MARX, Carlos, El capital, T. I V. II, "El proceso de producción del capital", Siglo XXI, Argentina, 2011, pp. 391-408; FOUCAULT, Michel, Vigilar y castigar, Siglo XXI, México, 1976, pp. 139-174; SIERRA ALVAREZ, José, El obrero soñado. Ensayo sobre el paternalismo industrial (Asturias, 1860-1917), Siglo XXI, Madrid, 1990, Caps. I, II y IV.

11 Sintéticamente recuperaremos la tesis de Sierra Álvarez que pondera la violencia como componente estructural de la relación capital-trabajo en el desarrollo de la gran empresa: “...el encarrilamiento hacia la fábrica y la adaptación productiva del trabajador, no parecen haberse producido espontáneamente. Uno y otra parecen haber sido, más bien, el resultado de la aplicación de técnicas conscientes, voluntarias, específicamente dirigidas a un fin: esas técnicas son las disciplinas industriales... Disciplinas por cuanto, en segundo lugar, la fábrica, su producto, es algo más que economía y técnica. Disciplina por cuanto, finalmente, la fábrica es, ante todo, violencia. Violencia ordenada, sistemas de relaciones de poder entre los hombres", SIERRA ALVAREZ, José, El obrero soñado..., Op. Cit., p. 15.

12 En nuestra reconstrucción de las prácticas empresariales seguiremos la noción de violencia simbólica desarrollada por el sociólogo Pierre Bourdieu. Para el autor la violencia simbólica es aquella que se despliega de forma invisible, soterrada, implícita o subterránea y que, por sus modalidades, oculta la matriz basal de las relaciones de fuerza en las cuales se configura. En este sentido, abordaremos 
planteos que definen la fábrica y la dinámica entre sus protagonistas a partir de considerar "la naturaleza contradictoria de la empresa como sistema de cooperación y dominio a un mismo tiempo", un marco de "cooperación autoritaria". ${ }^{13}$

Hacia 1960 el astillero empleaban aproximadamente 5000 operarios de planta permanente y 3000 empleados en empresas contratistas destinados a distintas áreas productivas. La actividad productiva requirió de mano de obra especializada conformada por oficios considerados de largo plazo y posibilitó la carrera profesional al interior de la fábrica. La relación laboral se identificaba con el segmento superior del mercado de trabajo producto- en términos comparativos- de la situación del conjunto de la clase obrera en la región, del nivel de ingreso medio-alto y de la estabilidad y movilidad laboral. ${ }^{14}$ Como consecuencia de estos elementos es posible identificar en el caso la conformación de un sistema de mercado interno de trabajo (MIT) inscripto en las líneas generales que compartían las grandes empresas dinámicas del período que por sus características productivas demandaban una fuerza de trabajo estable,

aquellas acciones empresariales que tuvieron implicancias en la acción obrera colectiva e individual operando fundamentalmente sobre la subjetividad de este colectivo. La amenaza constante y el riesgo de pérdida de la fuente de trabajo fue una de las expresiones de mayor contundencia en este sentido. Ver, BOURDIEU, Pierre y PASSERON, Jean-Claude, La Reproducción. Elementos para una teoría del sistema de enseñanza, Libro 1, Editorial Popular, España, 2001.

13 FERRAROTTI, Franco, Hombres y máquinas en la sociedad industrial, Labor, Barcelona, 1976, p.124 citado en SIERRA ALVAREZ, José, El obrero soñado..., Op. Cit., p. 20. Una primera aproximación a esta problemática se realizó desde una perspectiva comparativa entre las acciones empresariales de una empresa pública como el ARS y una industria privada. Ver BARRAGAN, Ivonne y RODRIGUEZ, Florencia, "Estrategias patronales y conflictividad obrera en grandes industrias dinámicas. Una mirada comparativa sobre los casos Propulsora Siderúrgica (PPS) y Astillero Río Santiago (ARS) de la región de Ensenada entre 1973 y 1975" ponencia presentada en VII Jornadas de Sociología de la Universidad Nacional de La Plata: "Argentina en el escenario latinoamericano actual: debates desde las ciencias sociales”, Diciembre de 2012 (ISSN 2250-8465). Disponible en: http://jornadassociologia.fahce.unlp.edu.ar/actas/BarraganRodriguez.pdf/view. [Consulta: 8 de febrero de 2013]

14 Para el caso del ARS Juliana Frassa pone en relevancia el rol de las trayectorias sindicales particulares en la comprensión de procesos de carácter global del mercado de trabajo y estructura económica a partir de la apropiación de este sistema de beneficios. Hemos abordado el caso aquí tratado en diálogo con lo que la autora indaga para el contexto de precarización laboral de la década de 1990. Ver FRASSA, Juliana, "Mercados internos de trabajo y relaciones laborales. La gestión del trabajo en una empresa estatal argentina en contextos de precarización", en Revista GTP Gestión de las personas y tecnologías. Universidad de Santiago de Chile, Mayo de 2010. Disponible en formato digital en:

http://www.revistagpt.usach.cl/sites/revistagpt.usach.cl/files/paginas/gpt07.pdf . [Consulta: 14 de febrero de 2013]. 
con una formación técnica específica vinculada al proceso productivo, en confluencia con la necesidad de cierto grado de identidad o lealtad de los operarios con la empresa. ${ }^{15}$

El conjunto de condiciones beneficiosas que constituían en parte la relación laboral contribuyeron a la configuración de elementos de identificación con la empresa y un orgullo obrero de largo alcance y múltiples implicancias. Es decir, las acciones del directorio de esta fábrica tendieron a ordenar las relaciones de producción a partir de la implementación de un conjunto de medidas complementarias a las nociones de control y vigilancia que conformaron un universo de beneficios complementarios al salario. En diálogo con esta perspectiva, nosotros haremos hincapié en las modalidades violentas de este accionar patronal. ${ }^{16}$

La estrategia integradora, según Frassa, tomó el siguiente carácter: "la dirección del astillero promovió entre sus trabajadores un sentimiento fuertemente nacionalista sustentado en el carácter público de la empresa y en su función de afianzar el desarrollo industrial del país. El impulso de este discurso a través de los años, sumado a los beneficios materiales y la estabilidad laboral que proveyó tradicionalmente el astillero, forjaron en los trabajadores una fuerte identidad sociolaboral relacionada íntimamente a la empresa". ${ }^{17}$ Algunos de los testimonios recabados dan cuenta de esta apelación simbólica que relaciona en forma directa la fábrica y la nación: “...el trabajo en el Astillero, no tenía ninguna voluntad de conseguir otro, porque trabajando en el Astillero vos trabajás para el pueblo, para la patria, es lo suficientemente complejo técnicamente para que estés aprendiendo todos los años de tu vida que vos quieras aprender, y además estatal". Al ser interrogado sobre las condiciones de trabajo el mismo trabajador expresaba: "Eran excelentes. Escuelas de fábrica, era un mundo. Vos podías ser analfabeta, mayor de edad, sin oficio y el astillero tomarte igual de peona, te permitía terminar la primaria, en 110 días te sacaba ayudante de algún oficio, electricista, maniobras, carpintería, albañil, tornero, pesador, ajustador, mecánico, pintor, soldador, lo que haga falta. En 110 días eras ayudante y después podías adelantar en la secundaria si querías y ya

15 Sobre la constitución de mercados internos de trabajo ver BURAWOY, Michael, El consentimiento en la producción. Los cambios del proceso productivo en el capitalismo monopolista, Ministerio de Trabajo y Seguridad Social, Madrid, 1989.

16 Siguiendo a Sierra Álvarez este señala que las técnicas de reclutamiento de trabajadores "parecen haberse desplazado entre dos polos: el estímulo y la coerción. Cuidadosamente dosificados, además, en función de la naturaleza del paciente: a los trabajadores de oficio, los menos, la zanahoria; a los trabajadores de origen campesino, los más, el palo". SIERRA ALVAREZ, José, El obrero soñado..., Op. Cit., p. 15.

17 FRASSA, Juliana, MUÑIZ-TERRA, Leticia, NACLERIO, Alejandro, "Trayectorias empresariales divergentes frente a contextos de privatización. Un estudio comparativo de dos empresas públicas argentinas", en Revista Economía, Sociedad y Territorio, El Colegio Mexiquense, México, enero-abril, 2010, V. X, No XXII, pp. 179-206 y 193. Disponible en formato digital en:

http://redalyc.uaemex.mx/src/inicio/ArtPdfRed.jsp?iCve=11112509007. [Consulta: 20 de febrero de 2013] 
eras ayudante. Cursos de perfeccionamiento del máximo nivel, comparado con los pibes de ahora, nosotros somos ingenierazos. Nos hemos especializado con lo máximo del mundo". ${ }^{18}$

Otro elemento en la construcción de disciplina industrial fue el recurso a la profundización de la diferenciación interna del cuerpo de operarios - escalafón- que parecía reificar la idea del obrero mejor pago, con beneficios relativos a su calificación, antigüedad e individualidad, tendiente a reforzar la distancia entre estamentos de obreros del ARS y entre éstos y los trabajadores empleados en ramas menos dinámicas de la región. ${ }^{19}$ La formación de una fuerza de trabajo de características como las descriptas fue una de las acciones de largo plazo de la dirección naval de la empresa. Parte de esta formación se realizaba a partir del ingreso de aprendices en la Escuela de Artesanos, posteriormente escuela Técnica Privada de Fábrica, donde egresaban con el grado de "ayudante obrero" mediante la instrucción con técnicos del astillero y profundizaban el oficio en el taller correspondiente bajo la guía de un capataz. ${ }^{20}$

La construcción de una fuerte identificación de los trabajadores con la empresa a partir de una relación laboral beneficiosa en un contexto de fuerte ordenamiento jerárquico de la fuerza de trabajo, basada en una organización estamental por el nivel de capacitación técnica, tiempo de permanencia en la fábrica y de disciplina militarizada puede interpretarse como una modalidad del paternalismo industrial de rasgos peculiares. ${ }^{21}$ Laura Badaloni retoma la

18 Entrevista realizada por la autora a Ángel en el primer trimestre de 2008.

19 El conjunto de condiciones beneficiosas en que se inscribía la fuerza de trabajo fueron institucionalizadas paulatinamente por la organización sindical mediante la negociación de tres Convenios Colectivos de Trabajo (CCT) a partir del año 1971. Fondo Documental Ministerio de Trabajo y Seguridad Social (MTySS), Dirección Nacional de Relaciones de Trabajo (DNRT), fondo Convenios Colectivos de Trabajo por actividad (CCTa). En adelante MTySS DNRT CCTa. Convenio Colectivo de Trabajo entre Astilleros y Fábricas Navales del Estado S. A. y la Asociación Trabajadores del Estado $\mathrm{N}^{\circ} 178 / 1971, \mathrm{~N}^{\circ} 24 / 1973$ y $\mathrm{N}^{\circ}$ 91/1975. Otra herramienta de fortalecimiento de la identificación de los trabajadores con el astillero fue aquella que instrumentó instancias de ingreso de los hijos o familiares de los trabajadores a la empresa ante la jubilación o accidente de trabajo estableciendo una serie de prioridades: "trabajador de la Base Naval Río Santiago, esposas e hijos de trabajadores fallecidos y/o en actividad, enviados por el gremio". MTySS DNRT CCTa. Convenio 178/1971, Asociación Trabajadores del Estado e/Astilleros y Fabricas Navales del Estado.

20 La Escuela Técnica "Astillero Río Santiago", es una escuela de educación técnica privada de fábrica, reconocida, en la actualidad, por la Dirección General de Cultura y Educación de la Provincia de Buenos Aires. Comenzó a funcionar el 30 de Junio de 1953 y su objetivo fundamental era "formar recursos humanos para la Industria Naval". Para un análisis de las funciones de las escuelas privadas de fábrica durante la ISI ver RODRIGUEZ, Florencia, "Escuelas privadas de Empresa. Notas iniciales sobre una estrategia del capital en las décadas del 60 y 70", en ELISALDE, Roberto y AMPUDIA, Marina (compiladores.), Trabajadores y educación, Ed. Buenos Libros, Buenos Aires, 2010.

21 Debemos una primera aproximación a estas nociones al interesante aporte realizado por la Dra. Ángela Vergara (University of San Diego, California). Exposición Mesa Redonda "Repensando o "trabalho" e os/as trabalhadores/as" "' VI Jornadas de Historia del Trabajo y II Seminario Internacional 
noción de paternalismo a partir de la identificación de dos componentes fundamentales, el empresario benefactor -elemento integrador-y el componente de control y vigilancia. ${ }^{22} \mathrm{De}$ este modo, permite visibilizar aquellas prácticas empresarias, que optaron por alternativas al puro control, y operaron, en la generalidad de los casos, como un conjunto de beneficios que se extendieron al ámbito de reproducción de la fuerza de trabajo con el objetivo de legitimar la estructura disciplinadora. Esta perspectiva nos permite abordar la construcción disciplinar a partir de su confluencia con un conjunto de beneficios laborales sin sustituirla: "por el contrario, creemos que represión y consenso son elementos constitutivos del paternalismo que busca moldear un tipo especial de trabajador: fuerte y eficaz en el trabajo; débil y obediente frente a los patrones". ${ }^{23}$

En este trabajo analizaremos la cuestión restringida a los beneficios propios de la relación laboral, es decir, aquellos que constituyen el ingreso monetario de los trabajadores y sus condiciones de trabajo, negociados colectivamente, sin ocuparnos de formas clásicas de la intervención paternalista en la esfera de reproducción de la fuerza de trabajo como la construcción de viviendas y enclaves productivos. ${ }^{24}$ En este sentido, hacia 1975 el Convenio Colectivo de Trabajo que comprendía a los trabajadores del astillero contenía cláusulas como aumento salarial automático en relación al costo de vida -específicamente por aumento del transporte-, premio por producción y botadura, guardería para los hijos de los trabajadores, etc. ${ }^{25}$

Mundos del Trabajo del GT Mundos del Trabajo de la ANPUH Río de Janeiro, noviembre de 2012. Vergara analiza comparativamente el desarrollo del paternalismo industrial en países periféricos. La singularidad en América Latina fue el carácter represivo de su desarrollo, que tuvo como objeto, principalmente, obliterar la generación de condiciones de empoderamiento de los trabajadores, aún de aquellos que pudieran considerarse "privilegiados" en términos de más altos ingresos.

22 BADALONI, Laura, "La familia ferroviaria a principios del siglo XX. Bienestar y lealtades de hierro en el Ferrocarril Central Argentino", en DICOSIMO, Daniel y SIMONASSI, Silvia (compiladores) Trabajadores y empresarios en la Argentina del siglo XX: indagaciones desde la historia social, Prohistoria Ediciones, Rosario, 2011, p. 146.

23 En un trabajo previo se abordó la construcción subjetiva de este modelo de trabajador desde la perspectiva de género, problematizando modelos de masculinidad presentes en la fábrica. Ver BARRAGAN, Ivonne y RODRIGUEZ, Florencia, "Clase, género, politización y violencia. Los casos del Astillero Río Santiago y Propulsora Siderúrgica 1974-1975”, en Revista de Estudios Marítimos y Sociales Universidad Nacional de Mar del Plata, en prensa.

24 Ver, entre otros, CABRAL MARQUES, Daniel, "La constitución de una "gran familia": trabajadores e identidades sociolaborales en las empresas extractivas estatales de la Patagonia Austral" en DICOSIMO, Daniel y SIMONASSI, Silvia (compiladores.), Trabajadores y empresarios en la Argentina del siglo XX..., Op. Cit., pp. 71-87.

25 BURGARDT, Clarisa, CAREDIO, Juan CUARTANGO, Carmen, NAUM, Griselda, SANDOVAL, Laura y PARIS, Rebeca, “Astillero Río Santiago. Trabajadores industriales y condiciones de 
En el período definido por el tercer gobierno peronista, en un contexto inflacionario creciente, que debilitó las bases de sustentación del Pacto Social, y de avance de la represión parapolicial sobre los sectores más movilizados de la clase obrera, los trabajadores del ARS, en concordancia con sectores organizados del movimiento obrero de la región industrial de La Plata, Berisso y Ensenada, sostuvieron una serie de conflictos y medidas de fuerza en defensa del nivel salarial "superior" de la fábrica, en mejora de las condiciones de trabajo y, crecientemente, cuestionando la conducción sindical burocrática más alineada a las propuestas integradoras de la dirección de esta fábrica. ${ }^{26}$

\section{Acción patronal y conflicto obrero}

El conjunto de las estrategias patronales puestas en práctica por la dirección del astillero, en el contexto de intensificación de las luchas sociales ocurrido entre los años 1973 y 1975 sufrieron cambios y redefiniciones. El período 1973-1975 condensó, por un lado, un proceso de profundización de la organización gremial y política en el lugar de trabajo. Por otra parte, en términos de acción empresarial, el mismo período presenta un crecimiento productivo sin precedentes. Este movimiento dual fue determinante en la configuración de un tipo particular de relación social de trabajo desde la gerencia.

A partir de 1971 las evidencias analizadas permiten identificar los primeros signos de profundización en la estrategia productivista de la empresa, cuyo mayor despliegue puede indicarse para el trienio aquí observado. Este período consolidó un proceso, de más largo alcance, que desde la década del sesenta sostuvo inversiones, modernización de equipos, ampliación de infraestructura, capacitación permanente de la mano de obra-sostenimiento del nivel de productividad y eficiencia-. La capacidad tecnológica del ARS alcanzó, medida en posibilidades de elaboración de acero, las $40.000 \mathrm{TN}$ (toneladas) por año, equiparable a la construcción de 5 buques de gran porte. ${ }^{27} \mathrm{El}$ aumento en el ritmo de producción se evidenció

trabajo" en Equipo Federal de Trabajo, Facultad de Ciencias Sociales-UNLZ-, 2007, NXXIII, pp. 37-65 y p. 47. Disponible en: http://www.eft.org.ar/pdf/eft2007_23pp37-65.pdf. [Fecha de consulta: 29 de agosto de 2013].

26 La historiadora Victoria Basualdo sostiene la tesis de la existencias de diferentes concepciones de la relación capital-trabajo en el plano de las conciencias de clase que disputan al interior de la clase obrera y se despliegan en la representación en el lugar de trabajo en términos de estrategias conciliadoras y confrontativas. AZPIAZU, Daniel, BASUALDO, Victoria y SCHORR, Martín, La industria y el sindicalismo de base en la Argentina, Cara o Ceca, Buenos Aires, 2010.

27 (Memorias y balances, AFNE, ejercicio 15) citado en RUSSO, Cintia, "Transformaciones territoriales y productivas en la Región Metropolitana Sur de Buenos Aires. El caso del Astillero Río Santiago", ponencia presentada en el XII Encuentro de Geógrafos de América Latina EGAL, Montevideo, abril de 2009.

62 
en el paso de la producción de un barco en 2 años a un barco en 9 meses. ${ }^{28}$ La racionalización patronal se expresó en la imposición de horarios continuos sin pagar derecho a turno, la extensión de la jornada y la creciente demanda de realización de horas extras. El directorio profundizó, en este marco, el proceso de terciarización laboral en las secciones de cobrería, montaje y carpintería de abordo. ${ }^{29}$

Las acciones patronales ante la conflictividad obrera variaron en relación al tipo de la demanda obrera. Las respuestas de la gerencia fueron inmediatas frente al reclamo salarial en la generalidad de los casos, independientemente del nivel de satisfacción que le dieran a los reclamos de los trabajadores. En contraposición, frente a las demandas vinculadas al proceso de producción, en especial en torno a temas del riesgo físico - que pareció configurarse como algo inherente a la actividad productiva misma- las reacciones fueron nulas o displicentes, moviendo el campo de acción al plano individual y reactivo de los operarios y al despliegue sin atenuantes de diversas manifestaciones de violencia como modalidades de impugnación de condiciones laborales consideradas injustas por los trabajadores.

Ejemplo de estas modalidades de reacción obrera y de la displicencia de la gerencia por las cuestiones referidas al riesgo físico en el proceso productivo, fue el accidente que sufrió un soldador quien murió quemado en el interior de un buque. En el testimonio de un operario del ARS identificamos una modalidad de acción desarticulada de repudio de lo que eran percibidas como condiciones de trabajo y explotación indignas pero no se expresaron en un reclamo sindical formal: "Nosotros sabíamos que la causa del accidente era por el mal estado de los equipos para soldar. Al otro día cuando llegamos al ARS, el compañero estaba totalmente carbonizado, pero aún vivía. Con un compañero que le decíamos Chirola, agarramos el primer equipo de soldar, lo arrastramos hasta la orilla del río y lo tiramos. Cuando nos damos vuelta vemos otros trabajadores que están haciendo lo mismo. Tiramos al agua por lo menos 15 equipos. La empresa no nos dijo nada. A la semana había equipos nuevos". ${ }^{30}$

La mencionada indiferencia patronal ante los reclamos por las condiciones de trabajo

28 Volante ¡Basta de atropello! Grupo obrero clandestino de astilleros Organización y lucha. DIPBA: Mesa B, Carpeta 39, Legajo 43, Ensenada, Astilleros "Río Santiago", T. I. Informe 13 de marzo de 1971. Departamento de búsqueda. Archivo de la Dirección de Inteligencia de la Policía de la Provincia de Buenos Aires en adelante referiremos a este archivo como DIPBA.

29 Un volante denunciaba: "Lo que no se dice es ¿por qué se contratan empresas privadas para trabajos que se pueden hacer en el ARS? ¿quiénes son los responsables de la falta de organización y planificación? ¿por qué faltan herramientas? ¿porqué hay laburantes sin nada de trabajo? ¿porqué no hay materiales en almacenes? ¿porqué se contrata personal superior para botonear en lugar de servir para mejorar la producción?....", DIPBA, Mesa B, Carpeta 39, Legajo 43, Ensenada, Astilleros "Río Santiago", T. I. Informe 14 de agosto de 1975. Agrupación Carlos Olmedo (ARS).

30 Testimonio de un trabajador en la Presentación de la Central de Trabajadores Argentinos (CTA) ante la Cámara Federal de La Plata. Comisión por la Verdad, hacia la justicia. La Plata, 22 de marzo de 2000, p. 10. 
tomó contundencia ante una serie creciente de accidentes de trabajo. Durante el proceso de pintura de un buque, en 1975, dos trabajadores murieron ahogados al fallar los frenos de la grúa flotante que los sostenía. Cayeron al río, sin protección de seguridad ni chalecos salvavidas, un trabajador murió ahogado luego de quedar inconsciente producto del golpe contra el casco del buque. Un grupo de compañeros de trabajo, al ver el accidente, se arrojaron al río en un intento por salvarles la vida, muriendo ahogado uno de ellos. ${ }^{31}$

En el campo de la lucha económica, uno de los recursos de la patronal consistió en manejar los tiempos de la negociación salarial y del otorgamiento de los aumentos. Lo hacía a partir de desplazar las responsabilidades materiales del salario operario del directorio de la planta a el directorio de la sociedad anónima de capitales públicos que administraba el astillero, Astilleros y Fábricas Navales del Estado (AFNE) y, posteriormente, al Ministerio de Defensa, o invocaba los límites impuestos por la paritaria nacional. Sin embargo, en diferentes momentos de la disputa económica, la estrategia consistió en la implementación en forma directa de aumentos salariales, ya fueran aumentos por fuera de convenio o de negociación intra-planta o aquellos realizados bajo la forma de premios por asistencia. En todos los casos, la aplicación del incremento salarial se realizó en función de la escala y la categoría laboral, lo cual reforzaba una dimensión material de estratificación interna del colectivo obrero. Esta estrategia colisionó con las demandas de la comisión interna combativa en la planta que reclamaba aumentos de suma fija, en oposición a las líneas del peronismo ortodoxo que lideraban la representación gremial en el plano regional quienes acordaban, en línea general, con la patronal resultando en la fortificación de la estratificación interna. ${ }^{32}$

Las organizaciones de base pugnaron por unificar y cohesionar al colectivo operario y demandaron incrementos de sumas fijas en repetidas oportunidades. Por ejemplo, en el conflicto del mes de noviembre de 1974. Los trabajadores en su conjunto reclamaban un aumento de

31 Ídem, p. 9. Este accidente no se encuentra datado con precisión en la fuente, ocurrió en diciembre de 1975 .

32 Diferentes agrupaciones políticas disputaron la representación sindical de base en el astillero en este período. La agrupación Azul y Blanca mantuvo en su poder la Seccional de Ensenada de ATE, controlada por sectores afines a Victorio Calabró, vicegobernador de la Provincia de Buenos Aires y representante de la derecha sindical peronista. Paralelamente, crecieron en el número de representantes de base electos las agrupaciones Gris, que era un desprendimiento de la Azul y Blanca alineada a Bidegain, Gobernador de la Provincia de Buenos Aires durante el Gobierno de Cámpora, vinculado a la izquierda peronista; la agrupación Celeste, controlada por la Juventud de Trabajadores Peronistas (JTP), organización sindical de base de la organización Montoneros; y la agrupación Marrón que respondía políticamente al Partido Socialista de los Trabajadores (PST), entre un sin número de identidades políticas que se encontraban presentes en esta fábrica de ocho mil trabajadores. La profundización de la dinámica de la representación sindical de base supera las posibilidades de este trabajo. MONTES, José, Astillero Río Santiago. Su historia y lucha relatada por sus trabajadores, La verdad obrera, Buenos Aires, 1999, p. 48. 
cien mil pesos Moneda Nacional $(\mathrm{m} \$ \mathrm{n})$ en el marco del Pacto Social. La patronal propuso otorgar un aumento escalonado, de acuerdo a los módulos de clasificación que implicaba un incremento de trescientos Pesos Ley para el peón de menor categoría y mil ciento cincuenta para el oficial. ${ }^{33} \mathrm{La}$ oferta fue rechazada por los trabajadores por constituir el porcentaje del $15 \%$ establecido por el gobierno nacional para aumentos salariales. ${ }^{34}$

A comienzos de 1975 se reforzó el pedido de sumas fijas y el reclamo de aumentos de emergencia. Hacia fines del mes de febrero el directorio propuso gestionar un premio por asistencia de treinta mil pesos $\mathrm{m} \$ \mathrm{n}$ en lugar de los diez mil que estaban establecidos previamente. ${ }^{35}$ Este conflicto salarial tuvo una resolución considerada aceptable por los trabajadores que obtuvieron, finalmente, un aumento de sesenta mil pesos $\mathrm{m} \$ \mathrm{n}$ independientemente del aumento salarial obtenido en la discusión colectiva. ${ }^{36}$ En el promedio del año 1975 la cuestión salarial retornó al centro de la escena por un pedido de incremento salarial que llevara el sueldo mínimo -peón- a los seiscientos quince mil pesos m\$n más un plus de cinco mil pesos $\mathrm{m} \$ \mathrm{n}$ por año de servicio. ${ }^{37}$ La patronal se mostró dispuesta a aceptar un mínimo de quinientos treinta mil. La disputa económica se estableció peso a peso y el directorio permanentemente apeló a la diferenciación de funciones/categorías.

En este punto, primó la estrategia de conciliación alrededor de las ideas que propugnadas por el directorio donde el trabajo colaborativo en el ARS confluía en la "construcción y en el bien de la patria". En el marco de esta negociación los directivos, en la asamblea, también plantearon "reclamos" a la parte obrera. Esperaban que los trabajadores prestaran "más apoyo a AFNE [Astilleros y Fábricas Navales del Estado], trabajando con más dedicación, y buena voluntad, y en disciplina, respetando los horarios establecidos para el desayuno y almuerzo, como reciprocidad al gesto de la empresa que se muestra permeable a sus inquietudes" ${ }^{38}$

Si bien a lo largo de la historia del ARS predominó una estrategia patronal de alternancia y complementariedad, la imposición de la línea coercitiva por sobre la de integración se consolidó con la dinámica social que se abrió con la muerte de Perón, el 1 de julio de 1974, y con la profundización de los efectos del Pacto Social. Durante el período analizado se detectó un incremento creciente en la vigilancia militar en la producción. Esto operó como una instancia de visibilización de la violencia en la explotación de una fuerza de trabajo que

33 El Peso Ley 18.188 fue la moneda vigente en la Argentina en el período 1970-1983, popularmente conocido como peso ley. Cada peso ley equivalía a 100 Pesos Moneda Nacional (m\$n). Así, por ejemplo, los de 100, 500 y 1.000 pesos m/n fueron convertidos a 1, 5 y 10 Pesos Ley respectivamente.

34 DIPBA, Mesa B, Carpeta 39, Legajo 43 “Astillero Río Santiago de Ensenada”, T. I, 13 de Noviembre de 1974.

35 Ídem, Folio 33-34, 19 de febrero de 1975.

36 Ídem, Folio 35, 27 de febrero de 1975. .

37 Ídem, Folio 54, 17 de junio de 1975.

38 Ídem, Informe 27 de febrero de 1975. Departamento de búsqueda. 
no podía ser disciplinada. La violencia intrínseca a su condición de autoridades militares se movió de un estado de latencia paulatinamente hacia un despliegue explícito y cada vez más permanente de materialidad sobre los cuerpos de los operarios. ${ }^{39}$

Un punto de inflexión en relación a la violencia en los planteos patronales se abordó a partir de las acciones desplegadas por el estallido de la Fragata Santísima Trinidad en confluencia con el proceso de intensificación de la militancia política en la fábrica donde organizaciones político-militares jugaron un rol destacado en la lucha político-gremial y el recurso a acciones armadas formó parte del repertorio de estrategias y formas de lucha. ${ }^{40} \mathrm{En}$ la madrugada del 22 de agosto de 1975, la agrupación Montoneros, en la fecha aniversario de los fusilamientos de Trelew, arguyendo que la "armada asesina que conduce el astillero hace contrataciones con el Reino Unido" hizo estallar una bomba en la fragata Santísima Trinidad, aparcada para su construcción en el astillero. ${ }^{41}$

En respuesta al atentado, la dirección de la empresa instaló un Infante de Marina cada tres operarios trabajando, se incrementaron las intervenciones y las formas de seguimiento. Los trabajadores identificaron este tipo de acción patronal como una reacción empresarial con ribetes revanchistas, la disposición de infantes navales en el espacio productivo reconfiguró la dinámica de representación sindical de base en particular y la dinámica obrera en general. Un testimonio da cuenta de las formas violentas de desmantelamiento de la organización en la fábrica: "Si vos lo tomas como acción militar de la organización dicen que fue espectacular, pero yo de bombas no entiendo. Lo que sí no tuvieron en cuenta es lo que se produjo adentro. Pasó de todo. Nos faltaba que nos pongan en la ametralladora contra la pared. Este accionar de Montoneros, yo sé que los compañeros se enojan cuando uno lo dicen pero esa es la verdad de lo que ocurrió adentro, vos podes preguntarle a otros compañeros, le permitió a la marina, porque estamos hablando de la marina, no estamos hablando de Roca, a que con eso los técnicos fueran a barrer, un desastre a nivel organizativo de lo que era esa organización de delegados de las fábricas. Lo hace pelota, porque éramos todos Montoneros, más o menos para ellos... Porque vos un técnico del astillero, imagínate, que es como decir

39 El desarrollo de modalidades diferenciadas de violencia material y simbólica y sus implicancias sobre los cuerpos de los trabajadores fueron abordadas previamente. Ver BARRAGAN, Ivonne, "Disciplinamiento industrial, represión y conflictividad obrera en una empresa estatal. Astillero Río Santiago (1973-1976)", ponencia presentada en las VI Jornadas de Historia del Trabajo y II Seminario Internacional Mundos del Trabajo del GT Mundos del Trabajo de la ANPUH Río de Janeiro, Río de Janeiro, noviembre de 2012.

40 Sobre la instrumentación de violencia política y sus implicancias en la lucha sindical ver LORENZ, Federico, Algo parecido a la felicidad. Una historia de la lucha de la clase trabajadora durante la década del setenta (1973-1978), Edhasa, Buenos Aires, 2013.

41 DIPBA, Sección "C" N ${ }^{\circ}$ 2111, Legajo 3760, "Atentado a la Fragata T-42 'Santísima Trinidad' amarrada en Astilleros Río Santiago 22 de Agosto de 1975", Folio 11: Comunicado refrendado por Montoneros al subdirector del Diario Clarín. 
Favaloro, hacen buques no hacen, que se yo, chapitas, lo agarra y le dicen gracias a lo que hicieron por tirar la fragata abajo, andá a barrer el taller. Utilizado de esa manera". ${ }^{42}$

En este momento se dio el cambio más significativo en términos de estrategias empresariales. Las modalidades de violencia que configuraron el accionar patronal se desplegaron simbólica y materialmente en las negociaciones salariales. Un nuevo conflicto salarial comenzó el 29 de octubre de 1975. Esta nueva instancia de disputa salarial posibilitó reconstruir parte de la estrategia patronal, su mirada sobre el conflicto de base, y el despliegue de una serie de elementos de modificación y manipulación de la identidad obrera con la fábrica y con los valores propugnados por la misma. ${ }^{43}$ Los trabajadores planteaban un aumento salarial que llevara el sueldo básico del peón a 1.200 .000 pesos $(\mathrm{m} \$ \mathrm{n})$. Durante el transcurso de una primera instancia del conflicto salarial fueron secuestrados seis operarios de planta, adscriptos al peronismo ortodoxo. Los trabajadores, en asamblea, identificaron un proceder conjunto de la dirección regional del sindicato y la patronal como una confusa táctica que tenía como objeto deslegitimar la lucha en relación a la oferta de un incremento salarial inferior al reclamado. ${ }^{44}$

Sin embargo, los trabajadores se movilizaron masivamente en defensa de los operarios secuestrados. La aparición con vida de los seis trabajadores coincidió con el extendido rumor que confirmaba la complicidad entre la patronal y la burocracia sindical en el secuestro. ${ }^{45} \mathrm{La}$ respuesta obrera resultó en la intensificación de las medidas de fuerza en función del reclamo

42 Entrevista realizada por la autora en 2009.

43 Un testimonio identifica la dirección de la empresa en ese tiempo en los siguientes términos: "Porque de esa manera nosotros salimos del estatuto. Y ya fuimos independizándonos porque nosotros en ese tiempo teníamos el director que era un capitán, un almirante. El jefe era un sub. oficial. Entonces los fueron sacando hasta que nos pasan al Ministerio de Defensa que nombra "AFNE" S.A. pero a la AFNE S.A. la maneja un capitán de la marina, pero ya era diferente. Es una S.A. no dependíamos directamente de la marina. Y entonces ahí es donde empezamos, que fue la época, hace poco que murió, un capitán que era presidente, era el capitán Carranza, de lo mejorcito que tuvimos, que vivía en La Plata. Él prácticamente defendía a la gente y cuando hubo un momento que nosotros no teníamos trabajo reunió a la gente y le dijo yo vengo a comunicarles que lamentablemente durante 6 meses no vamos a tener trabajo, pero quédense tranquilos que no vamos a tocar a nadie. Sí, que cada uno mejore las condiciones de los lugares donde está, se cortaba el pasto, se pintaba, higienizar todo para cuando esté. A los 6 meses se empezó el trabajo de agarrar los buques grandes, la cantidad de gente que entraba". Entrevista realizada por la autora en el primer semestre de 2008.

44 El 29 de octubre fueron secuestrados los operarios afiliados a la lista Azul y Blanca Carlos Lapasta, Aníbal Matracio, Nilo Bergenhau, Jorge Giménez, Juan Carlos Delleville y Néstor Toledo. DIPBA, Mesa "B", Carpeta 39, Legajo 43 Astillero Río Santiago de Ensenada, T. I, Diario Mayoría, 30 de octubre de 1975.

45 Los seis trabajadores fueron liberados el 30 de Octubre de 1975 en las inmediaciones de la sede sindical de ATE. Ídem, Folio 47. 
salarial original. ${ }^{46}$ Durante la segunda instancia del conflicto, en noviembre de 1975, fueron secuestrados tres delegados, esta vez de las líneas combativas. ${ }^{47}$ La escalada de la violencia patronal y la violencia política regional configuró un nuevo escenario político y gremial en la fábrica que, crecientemente, condicionó a los delegados combativos del astillero e incidió en la dinámica del conflicto.

En este marco, la patronal del astillero modificó radicalmente su estrategia. Su accionar estuvo cada vez más centrado en la violencia como mediador de la relación de clases en el espacio laboral. Expulsó la lucha de los operarios del ámbito de la fábrica con un lockout, de este modo, la dirección de la empresa redefinió el lugar del conflicto. Este tipo de prácticas combinó la violencia latente, por la amenaza de militares custodiando el proceso de producción; violencia material, a través de la represión de la Policía de la Provincia de Buenos Aires cuando los trabajadores intentaron realizar una asamblea en las inmediaciones de la planta, y la violencia simbólica que implicó el cierre de la planta en tanto posibilidad de pérdida de la fuente de trabajo.

El comunicado patronal sintetizaba la estrategia: "La empresa AFNE ha rechazado el pedido de aumento de 1.200.000 pesos básicos para el peón y los porcentajes correspondientes al resto del personal, por hallarse fuera de las posibilidades de la empresa y contravenirlas disposiciones del gobierno nacional sobre aumentos salariales ... en vista de lo resuelto por la asamblea realizada en la mañana del día 30 de concurrir el día 31 para mantenerse en estado de asamblea permanente hasta tanto la empresa acuerde los aumentos solicitados, se ha resuelto no permitir el acceso del personal al interior del Astillero, por cuanto están prohibidas las asambleas en horas de trabajo, lo que se mantendrá hasta tanto el personal, en una asamblea general, acepte la oferta de aumentos generales concedidos por la empresa en las circunstancias especiales del día 29 y se comprometa a trabajar ordenada y disciplinadamente... se previene que reanudado el trabajo, cualquier acto de indisciplina será sancionado con suspensión de tareas a los responsables, sección involucrada o al total del personal". ${ }^{48}$

El directorio de AFNE trató en asamblea ordinaria la situación ratificando el accionar del Presidente de la empresa en los siguientes términos: "En dicha ocasión les expresó que se mantendría la prohibición de ingresar al ARS hasta tanto se comunique al Señor Ministro de Defensa lo resuelto por el Directorio en relación a lo dispuesto por la Asamblea. Finalmente, luego de deliberar el Directorio Resolvió: 1) Ratificar lo actuado por el señor Presidente y

46 Ídem, Folio 49, El Día, 31/10/1975: "Nuevo planteo salarial de los trabajadores de Astilleros Río Santiago".

47 Los tres secuestrados fueron legalizados como detenidos de la Policía de la Provincia de Buenos Aires y liberados en el mes de febrero de 1976, tras cinco meses de detención, habiendo sido golpeados y torturados.

48 DIPBA, Mesa B, Carpeta 39, Legajo 43, Ensenada, Astilleros "Río Santiago", T. I. El Día, 01/11/1975. 
2) Aconsejar al señor Ministro de Defensa no acceder a lo solicitado por la Asamblea que informa la nota de ATE del $1 \%$ XI/75, ratificando la oferta hecha, sin ningún condicionamiento y manteniendo una vigilancia especial hasta tanto se evidencie un estado normal de disciplina en el ARS" ${ }_{49}$

Esta operación, que conjugó violencia simbólica y material, hacia la fuerza de trabajo tuvo efectos sobre sus expresiones individual y colectiva al provocar un quiebre en la solidaridad..$^{50}$ La pérdida real y potencial de la fuente de ingresos tuvo como consecuencia, en un contexto de profundización de la violencia política regional, el quiebre de la unidad obrera y la acción colectiva. El riesgo, esta vez impuesto sobre la fuente de trabajo, se proyectó de manera violenta sobre los distintos sujetos que protagonizaban la representación gremial y constituyó un recurso eficaz a la hora de profundizar los enfrentamientos entre las distintas agrupaciones obreras. Este quiebre colectivo se expresó de diferentes formas, un volante indicaba: "Hoy como el viernes y el lunes los que hace años que trabajamos en este Astillero, vemos que esta situación se la debemos a la acción de los Troskos, Montos, Comunachos, a la Judía Matilde que se han pasado jodiendo con pedidos pelotudos... A ver que hacen ahora los chantas troskos, montos, comunachos y la judía Matilde, si llegan a cesantear a algunos de nosotros compañeros, o si se llevan la Fragata y el San Antonio a Dársena Norte para terminarlos, gracias a la influencia de nuestro cornudo Ministro de Defensa que, además ya ha dicho "que para trabajar así cerramos el Astillero hasta febrero y lo depuramos de vagos y activistas", o se olvidan de 1962. Mientras tanto nosotros los que llevamos años trabajando en la empresa miramos como unos pelotudos que nos llevan como ovejas siguiendo a los

49 Fondo Documental AFNE, Archivo Intermedio del Archivo General de la Nación (AGN), Actas de Directorio de la AFNE correspondiente al año 1975, Acta de Directorio $\mathrm{N}^{\circ} 155$ del Libro $\mathrm{N}^{\circ} 2$. El Presidente Capitán de Navío Carranza, a quien un referente sindical mencionaba en la cita al pie 37 de este trabajo en este caso promovió un endurecimiento de las posiciones empresariales frente al colectivo obrero. Por su parte, Cintia Russo recupera una expresión de la misma gestión empresarial sobre la necesidad de proteger la fuerza de trabajo: "Cuando el trabajo escasea no es conveniente desprenderse de personal sobrante y retomarlo cuando este aumente. Si se procediera así difícilmente se recuperaría al personal perdido, ya absorbido por otras actividades. Sería necesario reclutar y adiestrar nuevos operarios y soportar el desajuste considerable entre el momento que se los requiere y el momento en que se encuentran capacitados con un alto costo de adiestramiento" (AFNE, Memorias y Balances, ejercicio 18). RUSSO, Cintia, "Transformaciones territoriales y productivas en la Región Metropolitana...", Op. Cit., p. 7.

50 En el Acta de Directorio de AFNE N 156 de fecha 13 de Noviembre de 1975 consta la puesta a disposición de la renuncia del Presidente de la empresa Capitán de Navío Carranza dada la situación de conflicto en el ARS la cual fue rechaza por unanimidad por el Directorio de la AFNE "por afectar en las actuales circunstancias el funcionamiento regular de la Empresa". 
chantas. Esto no va más, luchemos para que se reabra la fuente de trabajo y que se limpie tanto de abajo como de arriba de "zurdos" y corrompidos nuestro querido astillero". ${ }^{51}$

La mediación de violencia en lugar de las estrategias consensuales y negociadoras anteriores a 1974 continuó durante primeros meses de 1976. La sistematización de la represión de las fuerzas paramilitares de la Triple A, el secuestro y asesinato de delegados del astillero y de fábricas de la región conllevó la conformación de una comisión de representantes sindicales a fin de solicitar la intervención y gestión en la liberación de los trabajadores secuestrados del Director del astillero. ${ }^{52}$ La respuesta de la dirección de la fábrica fue comprometer su ayuda a cambio únicamente del levantamiento de las medidas de fuerza. ${ }^{53}$

En este contexto de profundización de la violencia política contra los sectores obreros más movilizados de la región, el Directorio de la AFNE analizó en la Asamblea Ordinaria de 4 de marzo de 1976 una nueva solicitud de aumentos salariales de los trabajadores y dejó constancia del "Proyecto del Comando General de la Armada de establecer una zona militar dentro del ARS y las nuevas medidas de seguridad tomadas en la construcción "T42" y en el "B.D.T.". El proyecto de zona militar en el ARS está a consideración del Ministerio de Defensa" 54

51 Volante Obreros Justicialistas del ARS, DIPBA Mesa B, Carpeta 39, Legajo 43 "Astillero Río Santiago de Ensenada", T. I, Folio 64. Algunos volantes amenazan a los delegados combativos de ser "ajusticiados". Ídem, Folio 66.

52 El 19 de febrero, dos días después de recuperar la libertad tras una detención de varios meses, fue secuestrado y asesinado el técnico del astillero Alcides Méndez Paz. COMISIÓN NACIONAL SOBRE LA DESAPARICIÓN DE PERSONAS (CONADEP), Informe CONADEP Nunca Más. Anexos, EUDEBA Buenos Aires, 2006, T. II Pág. 1064.

53 DIPBA, Mesa B, Carpeta 39, Legajo 35 "Coordinadora de Gremios-Comisiones Internas y Delegados en lucha La Plata, Berisso y Ensenada", Folio 6, 19 de enero de 1976. En el orden del día la Asamblea Ordinaria del Directorio de la AFNE de fecha 2 de Febrero de 1976, Acta ${ }^{\circ} 161$, consta “1) Paro de las actividades del ARS resuelto por una asamblea como consecuencia del secuestro y detención de operarios pertenecientes a empresas de la zona... 3) Nota de la A.T.E. referente a la desafiliación de todo el personal del ARS a la D.I.B.A. y la contestación que se formulara a la misma señalándole las consecuencias e inconvenientes que ello traería para el personal de la Empresa...”. En la misma se resolvió: a) Consideración de la aplicación del Decreto $\mathrm{N}^{\circ} 350 / 75$ : Aplicar el aumento dispuesto por el Decreto mencionado y en caso de que la Asociación Trabajadores del Estado (A.T.E.) pida acogerse al Art. $3^{\circ}$ del Decreto citado, autorizar a la presidencia a aplicar un aumento del $18 \%$ sobre el total de las remuneraciones percibidas el 31 de diciembre de 1975 , a partir del $1^{\circ}$ de enero de 1976.

54 Ídem, Acta $\mathrm{N}^{\circ} 163$. En el acta $\mathrm{N}^{\circ} 164$, de fecha 10 de marzo de 1976, consta la presentación mediante T.I. (trámite interno) $\mathrm{N}^{\circ} 1666 / 76$ de la renuncia indeclinable del Presidente de la Empresa C. de Navío Enrique Carranza, de tres directores y un síndico, rechazando el Directorio la presentación de las mismas pero sometiendo su aceptación final a la realización de una Asamblea Extraordinaria de Accionistas a realizarse el 18 de marzo de 1976. 
Finalmente, acercándonos a la obliteración de la acción colectiva por la represión sistemática, esta vez a manos del aparato del Estado, el 18 de marzo de 1976, los trabajadores iniciaron un paro progresivo por aumento salarial. Al día siguiente al inicio de la medida de fuerza fueron secuestrados y asesinados tres delegados. ${ }^{55}$ Ante el desarrollo de este nuevo reclamo la dirección de la empresa procedió nuevamente al cierre de la empresa en lo que consideró una situación de abierta rebeldía de los trabajadores. En los asuntos tratados en el orden del día de la reunión del Directorio de la AFNE S. A. consta la siguiente reconstrucción del conflicto: “ $1^{\circ}$ ) El día 17/III/76 el personal del ARS efectuó una asamblea dentro del ámbito del Astillero, sin autorización, disponiendo en la misma el cese de actividades por una hora para ese día y de dos horas para el día siguiente; $2^{\circ}$ ) Que ante esta circunstancia, la Empresa intimó al personal a normalizar las tareas por Disposición $\mathrm{N}^{\circ} 24 / 76$ de la Gerencia de Administración de fecha $17 /$ III/ $/ 76 ; 3^{\circ}$ ) Que obstante el personal continuó con las medidas de fuerza, efectuando el día 18/III/76 un paro de dos horas, que se continuaría al día siguiente con un paro de tres horas y la realización de una asamblea dentro del ámbito del Astillero, a pesar de la intimación expresa de la citada resolución y la falta de autorización. El día 19/ III/76 se recibió la nota $\mathrm{ATE}^{\circ}{ }^{139 / 76}$ (T.I. A.2078/76); $4^{\circ}$ ) Que todo lo anterior configuraba una abierta situación de rebeldía con el agravante de que la parte gremial no había cursado aún la comunicación oficial en la que expresara los motivos que la impulsan a tan inconsulta medida y que no existe ninguna situación conflictiva con la Empresa; ... $6^{\circ}$ ) Que la información expuesta precedentemente se puso en conocimiento del Señor Comandante General de la Armada, quién autorizó el cierre temporario del ARS con el objetivo de proteger la integridad física de personas y bienes del Establecimiento...". ${ }^{56}$ En una solicitada la gerencia de la empresa expresaba: "La medida de carácter temporal, se había adoptado en virtud de actos de indisciplina laboral y para preservar la seguridad interna del establecimiento". ${ }^{57}$

El recurso al cierre de la fuente de trabajo sumado a la creciente represión de los delegados de sector y representantes sindicales en la región re-configuró las condiciones de posibilidad de la acción colectiva en el período previo a la consumación del golpe de Estado y constituyó las condiciones de quiebre e indefensión en que este colectivo obrero enfrentó los hechos del 24 de marzo de 1976. ${ }^{58}$

55 Fortunato Agustín Andreucci, Jorge Pedro Gutzo y José Luis Lucero. COMISIÓN NACIONAL SOBRE LA DESAPARICIÓN DE PERSONAS (CONADEP), Informe..., Op. Cit., T. I y II, p. 981 y p. 1037.

56 AFNE, Reunión Directorio, 25 de marzo de 1976, Acta №167.

57 El Día, 21/03/1976.

58 Para un abordaje sobre la magnitud del proceso represivo implementado sobre este colectivo obrero en BARRAGAN, Ivonne, "Acción obrera durante la última dictadura militar, la represión en una empresa estatal. Astillero Río Santiago (1974-1984)" en BASUALDO, Victoria (coordinadora) La clase trabajadora argentina en el Siglo XX..., Op. Cit. 


\title{
Palabras finales
}

La reconstrucción realizada permite sostener que la fisonomía del caso radica en que la autoridad que gerenciaba el astillero propició una organización interna jerarquizada y burocrática, con énfasis en modalidades de autoridad militar, que recurrió simbólicamente a una modalidad de gestión de la fuerza de trabajo donde los intereses empresariales se presentaron como idénticos al crecimiento nacional y al beneficio obrero. Esta composición, desplegada sobre la materialidad del proceso de trabajo, promovió una subjetividad obrera que vinculó de forma directa la actividad productiva a la "construcción de la nación" en el marco de una relación contractual beneficiosa.

La patronal de esta fábrica llevó a cabo en el largo plazo acciones y prácticas gerenciales diferenciadas tendientes a reificar modalidades de subordinación del trabajo, promotoras de identidad y lealtad de los trabajadores con la empresa, con matices de negociación ante las problemáticas planteadas por la parte obrera, pero que frente a procesos de profundización de la organización de base y de conflictividad en la planta, se anclaron cada vez más en la puesta en práctica de la violencia material y simbólica como mediación de la relación social de trabajo a fin de recomponer la hegemonía al interior del astillero.

A partir de la reconstrucción de la especificidad esta dinámica en el lugar de trabajo y la puesta en diálogo con una serie de aportes teóricos sobre el paternalismo industrial se hilvanó la tesis sobre la complementariedad de las estrategias patronales. La singularidad del caso, donde una fuerza militar gestionaba un colectivo obrero en una empresa estratégica de capitales públicos, permitió identificar que ante el desafío al orden industrial planteado por el trabajo, las formas benefactoras y de integración hicieron eclosión frente a una política empresarial basada en una serie de acciones disciplinadoras de carácter crecientemente violento. Finalmente, la clausura de la acción obrera en el contexto dictatorial y el carácter revanchista de la represión volcada sobre los trabajadores del ARS constituyeron a este caso en la empresa con el mayor número de trabajadores y representantes de base desaparecidos y asesinados durante la última dictadura militar en Argentina. ${ }^{59}$

\author{
Recibido: 05/05/2013 \\ Aceptado: 15/08/2013
}

59 De acuerdo a la evidencia recabada fueron detenidos-desaparecidos cuarenta y cuatro trabajadores y representantes sindicales del ARS durante el autodenominado Proceso de Reorganización Nacional (PRN) (1976-1983). Los once trabajadores del astillero, asesinados, comprenden un período temporal más amplio, ya que algunos de los asesinatos ocurrieron durante el desarrollo de conflictos sindicales durante el año 1975. 